Article

\title{
Porous Oxygen-Doped g- $\mathrm{C}_{3} \mathrm{~N}_{4}$ with the Different Precursors for Excellent Photocatalytic Activities under Visible Light
}

\author{
Jiajing Zhang, Yongjie Zheng *, Heshan Zheng, Tao Jing, Yunpeng Zhao and Jingzhi Tian *
}

Citation: Zhang, J.; Zheng, Y.; Zheng, H.; Jing, T.; Zhao, Y.; Tian, J. Porous Oxygen-Doped $g-\mathrm{C}_{3} \mathrm{~N}_{4}$ with the Different Precursors for Excellent Photocatalytic Activities under Visible Light. Materials 2022, 15, 1391. https://doi.org/10.3390/ ma15041391

Academic Editor: Dirk Poelman

Received: 23 November 2021

Accepted: 20 January 2022

Published: 14 February 2022

Publisher's Note: MDPI stays neutral with regard to jurisdictional claims in published maps and institutional affiliations.

Copyright: (C) 2022 by the authors. Licensee MDPI, Basel, Switzerland. This article is an open access article distributed under the terms and conditions of the Creative Commons Attribution (CC BY) license (https:// creativecommons.org/licenses/by/ $4.0 /)$.
School of Chemistry and Chemical Engineering, Qiqihar University, Qiqihar 161006, China; zhangjiajing_1994@163.com (J.Z.); zhengheshan001@163.com (H.Z.); jtkr@163.com (T.J.); zhyypp@163.com (Y.Z.) * Correspondence: zyj1964@163.com (Y.Z.); tjz6666@163.com (J.T.); Tel.: +86-0452-2738-152 (Y.Z.)

\begin{abstract}
Antibiotic contamination has received widespread attention globally. In this work, the oxygen-doped porous graphite carbonitride $\left(\mathrm{g}-\mathrm{C}_{3} \mathrm{~N}_{4}\right)$ was prepared with urea and ammonium oxalate (CNUC) or urea and glycine (CNUG) as precursors by thermal polymerization. Using bisphenol A (BPA) as a probe and CNUC or CNUG as photocatalysts, the removal performance test was carried out. Meanwhile, all prepared photocatalysts were characterized by XRD, FT-IR, SEM, TEM, XPS, UV-Vis DRS, PL and EIS. Under visible light irradiation, both CNUC and CNUG exhibited about seven and five times greater photocatalytic activity than that of pure $\mathrm{g}-\mathrm{C}_{3} \mathrm{~N}_{4}$, respectively. The radical capture experiments verified that superoxide radicals $\left(\bullet \mathrm{O}_{2}{ }^{-}\right)$and holes $\left(\mathrm{h}^{+}\right)$were the main active species in the photocatalytic degradation of BPA by CNUC, and the possible photocatalytic mechanism of CNUC was proposed. In addition, all these results indicate that CNUC catalyst can effectually inhibit the photocorrosion and keep superior stability. The proposed technique provides a prospective approach to develop nonmetal-modified photocatalysts for future applications.
\end{abstract}

Keywords: copolymerization; $\mathrm{g}-\mathrm{C}_{3} \mathrm{~N}_{4}$; oxygen-doped; visible light degradation; photocatalysis

\section{Introduction}

Bisphenol A (BPA), also named diphenol-based propane, is a low-toxic compound and an important raw material for the production of polycarbonate, epoxy resin, phenolic resin, some polysulfones, and some special materials [1]. Because of its light weight, transparency, and toughness, BPA is widely used in manufacturing notebooks, mobile phones, baby bottles, and other food and beverage containers [2]. However, experiments have proved that BPA has an endocrine disruptor effect, which can be transferred to the environment through plastics, and it is increasingly detected in water environments, posing a serious threat to the ecosystem [3]. At present, a variety of treatment technologies have been studied, such as chemical reactions [4], biodegradation [5], and physical absorption [6]. The removal of BPA could reduce harm to the human body and could reduce water pollution. Therefore, removing BPA is the focus of current research. Among various methods, photocatalytic technology is the most likely and effective method to remove phenolic pollutants in water [7]. Photocatalytic technology converts low-density solar energy into high-density chemical energy and can directly use solar energy to degrade and mineralize various organic pollutants in water and air. It has the advantages of mild reaction conditions, no pollution, and low cost [8], making it an ideal piece of technology for environmental pollution control and clean energy production. However, the current problem with photocatalysts is the rapid recombination of photogenerated electron-hole pairs and the narrow photoresponse range of the photocatalyst. [9]. Therefore, the development of high-efficiency photocatalysts is still one of the focuses and core issues of photocatalysis scientific research at present, and it will likely still be in the future.

Graphite carbonitride $\left(\mathrm{g}-\mathrm{C}_{3} \mathrm{~N}_{4}\right)$ has gradually become a research hotspot since its discovery in 2009 as an n-type nonmetallic polymer semiconductor for the photocatalytic 
production of hydrogen [10]. The uniqueness of its semiconductor energy band structure and favorable chemical stability has been extensively used in the fields of photocatalytic hydrogen production [11], conversion of environmental pollutants [12], and reduction of carbon dioxide [13], and has always attracted people's attention. As a photocatalytic material, it has many advantages: (1) Carbon nitride has a unique layered structure, which can provide more active reaction centers and play a role in many application fields. It can also improve or strengthen the functionality of the host material, endowing it more excellent performance. (2) Carbon nitride itself is stable and not only has the advantages of organic polymer molecules and layered structure but also has great doping changes. In addition, it has a simple composition, no metal elements and does not cause secondary pollution to the environment during use. (3) The bandgap energy of carbon nitride materials is higher than those of conventional semiconductors. Smaller band gap materials help to better absorb and utilize sunlight and have good application prospects in many fields, such as environmental purification [14]. However, the currently synthesized g- $\mathrm{C}_{3} \mathrm{~N}_{4}$ still has shortcomings, such as small specific surface area and too fast photo-generated carrier recombination, resulting in low photocatalytic activity.

In recent years, researchers have been committed to studying the modification of g- $\mathrm{C}_{3} \mathrm{~N}_{4}$ to improve the photocatalytic efficiency of g- $\mathrm{C}_{3} \mathrm{~N}_{4}$. The modification methods include element doping, the formation of heterostructures with other semiconductors, and the construction of micro-morphology [15]. In these modification methods, the material for constructing the porous structure could increase the specific surface area of the catalyst and increase the carrier diffusion channel, thereby improving the light trapping capacity of the catalyst, accelerating the mass transfer process, leading to destruction and having more reactive sites. [16]. Besides, the nonmetallic elements used for doping include $C$, $\mathrm{N}, \mathrm{O}, \mathrm{P}, \mathrm{B}, \mathrm{S}$, among others, which can further effectively improve $\mathrm{g}-\mathrm{C}_{3} \mathrm{~N}_{4}$ by changing the chemical properties of $\mathrm{g}-\mathrm{C}_{3} \mathrm{~N}_{4}$, narrowing the bandgap, and adjusting the electronic structure [17]. Regarding photocatalytic performance, Chen [18] had reported that porous oxygen-doped graphitic carbon nitride nanosheets $\left(\mathrm{xSO}-\mathrm{g}-\mathrm{C}_{3} \mathrm{~N}_{4}\right)$ were prepared using urea and sodium oleate via thermal copolymerization. The change in electronic structure promotes the formation of the intermediate band gap, resulting in $\mathrm{xSO}-\mathrm{g}-\mathrm{C}_{3} \mathrm{~N}_{4}$ having good photocatalytic activity. Similarly, Zhu [19] prepared nitrogen-doped g- $\mathrm{C}_{3} \mathrm{~N}_{4}(\mathrm{NCN})$ with a highly narrow bandgap and implemented it for the photodegradation of phenols. NCN (2:2) showed about two times higher photodegradation efficiency and three times higher rate permanent than the pristine g- $\mathrm{C}_{3} \mathrm{~N}_{4}$. However, some disadvantages may exist in $\mathrm{S}$ or $\mathrm{P}$ doping, such as the generation of by-products and the dissolution of heteroatoms. In addition, during the current element doping to prepare porous $\mathrm{g}-\mathrm{C}_{3} \mathrm{~N}_{4}$ materials, in the preparation process, most of the templates $\left(\mathrm{SiO}_{2}\right.$ [20] and SBA-15 [21], etc.), strong acids and alkalis were used for post-processing $\left(\mathrm{H}_{2} \mathrm{O}_{2}\right.$ [22] and $\mathrm{HNO}_{3}$ [23], etc.). Therefore, it is necessary to develop a simple and green method to overcome the above shortcomings and apply them in practice.

Herein, two oxygen-doped porous g- $\mathrm{C}_{3} \mathrm{~N}_{4}$ photocatalysts were successfully prepared by the thermal copolymerization of two different precursors. It is worth noting that, compared with pure $\mathrm{g}-\mathrm{C}_{3} \mathrm{~N}_{4}$, the two photocatalysts had significantly improved photodegradation efficiency of bisphenol A (BPA) and had excellent stability under visible light irradiation. Through the characterization of CNUC and CNUG's morphology, chemical composition, light absorption and photoelectric properties, the reasons for their interactive photocatalytic effect were explained. The as-prepared catalyst had a large surface area and an extended light absorption region. Meanwhile, the two catalysts were compared to determine the optimal preparation method. Finally, the intermediates of the catalyst to degrade BPA were explored by LC-MS, and the possible degradation mechanism of the catalyst was proposed. 


\section{Experimental Section}

\subsection{Materials and Reagents}

All chemical reagents and materials were purchased and used without further purification. Urea $\left(\left(\mathrm{NH}_{2}\right)_{2} \mathrm{CO}\right)$ was bought from Profile (Wuxi, China). Ammonium oxalate $\left(\left(\mathrm{NH}_{4}\right)_{2} \mathrm{C}_{2} \mathrm{O}_{4}\right)$ and glycine $\left(\mathrm{C}_{2} \mathrm{H}_{5} \mathrm{NO}_{2}\right)$ were purchased from Aladdin (Shanghai, China). Ultrapure water $(>18.2 \mathrm{M} \Omega$ ) was used in this study.

\subsection{Preparation}

The detailed preparation processes were provided in the Supplementary Materials section.

\subsection{Characterization}

The crystal structure of the prepared samples was characterized by X-ray diffraction (XRD), and the diffraction system was German BRUKER-AXS D8(Beijing Beishide Instrument Co., Ltd., Beijing, China). The chemical composition and element bonding of the prepared samples were analyzed by X-ray photoelectron spectroscopy (XPS) (Beijing Oubotong Optical Technology Co., Ltd., Beijing, China), and the XPS spectrum was recorded on the ESCALAB250Xi system equipped with a monochromatic Al K $\alpha$ X-ray source. The chemical composition of the sample and the nature of the chemical bond are characterized by Fourier Transform Infrared (FT-IR) Spectrometer, Nicolet380 (Beijing Beishide Instrument Co., Ltd., Beijing, China.). The surface and micro morphology of the sample were characterized by using a scanning electron microscope (SEM) (S-3400) and a transmission electron microscope (TEM) (Tecnai) of Hitachi, Japan. The optical properties of the material were characterized by a diffuse reflectance spectrophotometer (UV-vis DRS, UV-3900) manufactured by Beijing General Analysis Co., Ltd., Beijing, China. The electrochemical properties of the material were recorded using the $\mathrm{CHI} 660 \mathrm{~B}$ electrochemical system (Beijing Pofila Co., Ltd., Beijing, China) to record the impedance spectroscopy (EIS) Nyquist plot.

\subsection{Photocatalytic Degradation of BPA}

BPA was used as the target pollutant to evaluate the photocatalytic activity of the catalyst. We used a wavelength above $420 \mathrm{~nm}$ and a $500 \mathrm{~W}$ xenon lamp as a light source. First, we dispersed $50 \mathrm{mg}$ of photocatalyst in $50 \mathrm{~mL}$ of BPA aqueous solution $(20 \mathrm{mg} / \mathrm{L})$, and magnetically stirred for $10 \mathrm{~min}$ in the dark to ensure that the adsorption-desorption equilibrium was reached before irradiation. During the reaction, stirring was continued to ensure that the mixture was in suspension. Every $10 \mathrm{~min}$, we used a pipette to take out $5 \mathrm{~mL}$ of the solution and filter it with a $0.22 \mu \mathrm{m}$ microporous membrane to remove the catalyst. Finally, high-performance liquid chromatography (HPLC) was used to measure the bisphenol A solution. We eluted bisphenol A with mobile phase methanol and water (55:45 by volume). The degradation rate of BPA was calculated using the following Equation (1):

$$
\eta=\frac{C_{0}-C_{t}}{C_{0}} \times 100
$$

where $C_{t}$ is the concentration of BPA at time $t$ and $C_{0}$ is the initial concentration of BPA before the reaction.

\section{Result and Discussion}

\subsection{Photocatalytic Performances Test}

Under the irradiation of visible light, using the prepared catalyst as a probe and BPA as the target pollutant, the photocatalytic properties of pure $\mathrm{g}-\mathrm{C}_{3} \mathrm{~N}_{4}, \mathrm{CNUC}$ and CNUG were explored. As shown in Figure 1a, the degradation rate of BPA with pure g- $\mathrm{C}_{3} \mathrm{~N}_{4}$ as a photocatalyst was only $14 \%$ after a reaction of $60 \mathrm{~min}$, indicating that only $14 \%$ BPA was removed. Compared with pure $\mathrm{g}-\mathrm{C}_{3} \mathrm{~N}_{4}$, the four $\mathrm{CNUC}_{1-4}$ samples presented higher 
photocatalytic efficiency for BPA degradation. The degradation rate of pure BPA is $11 \%$. The degradation rate of $\mathrm{BPA}$ with $\mathrm{CNUC}_{1}, \mathrm{CNUC}_{2}, \mathrm{CNUC}_{3}$, and $\mathrm{CNUC}_{4}$ as photocatalysts was $48 \%, 52 \%, 81 \%$, and $53 \%$, respectively, corresponding to $3,4,7$, and 4 times higher rates than that of BPA with pure g- $\mathrm{C}_{3} \mathrm{~N}_{4}$, as a photocatalyst. The photodegradation performance was observed to increase with the increase in $\left(\mathrm{NH}_{4}\right)_{2} \mathrm{C}_{2} \mathrm{O}_{4}$ loading from 1 to $3 \mathrm{mmol}$ and deteriorated with a further increase in $\left(\mathrm{NH}_{4}\right)_{2} \mathrm{C}_{2} \mathrm{O}_{4}$ loading to $4 \mathrm{mmol}$, probably due to the blocking effect of light absorption when a higher amount of $\left(\mathrm{NH}_{4}\right)_{2} \mathrm{C}_{2} \mathrm{O}_{4}$ was incorporated. Similar phenomena were observed for CNUG samples, as shown in Figure $1 \mathrm{~b}$. The degradation rate of BPA with $\mathrm{g}-\mathrm{C}_{3} \mathrm{~N}_{4}, \mathrm{CNUG}_{1}, \mathrm{CNUG}_{2}, \mathrm{CNUG}_{3}$, and $\mathrm{CNUG}_{4}$ as photocatalysts was $35 \%, 62 \%, 72 \%$, and $42 \%$, respectively, corresponding to a $2.5,4,5$, and 3 times higher rate than that of BPA with pure g- $\mathrm{C}_{3} \mathrm{~N}_{4}$ as a photocatalyst. Among all of the $\mathrm{CNUC}$ and $\mathrm{CNUG}$ samples, $\mathrm{CNUC}_{3}$ presented the best performance. The photocatalytic degradation kinetics of BPA could be well expressed by pseudo-first-order reaction using the following equation:

$$
-\ln \left(C_{t} / C_{0}\right)=k t
$$

where $C_{t}$ is the concentration of BPA at a specific time $t, C_{0}$ is the original concentration, and $k$ is the rate constant. As shown in Figure 1c, these BPA photodegradation reactions followed first-order kinetics closely. The value of $\mathrm{k}$ was calculated to be $0.0125,0.0165,0.0278$, and $0.0183 \mathrm{~min}^{-1}$ for BPA with $\mathrm{CNUC}_{1}, \mathrm{CNUC}_{2}, \mathrm{CNUC}_{3}$, and $\mathrm{CNUC}_{4}$ as photocatalysts, respectively, corresponding to $5,7,12$, and 8 times faster than that of BPA with pure g- $\mathrm{C}_{3} \mathrm{~N}_{4}$ as a photocatalyst. Figure $1 \mathrm{~d}$ presents the pseudo-first-order fitting for BPA with CNUG as a photocatalyst. The obtained rate constant for $\mathrm{CNUG}_{1}, \mathrm{CNUG}_{2} \mathrm{CNUG}_{3}$, and $\mathrm{CNUG}_{4}$ was $0.0090,0.0091,0.0207$, and $0.0072 \mathrm{~min}^{-1}$, respectively. The highest rate constant observed for BPA with $\mathrm{CNUG}_{3}$ as a photocatalyst was 9 times higher than that for BPA with pure g- $\mathrm{C}_{3} \mathrm{~N}_{4}$ as a photocatalyst.
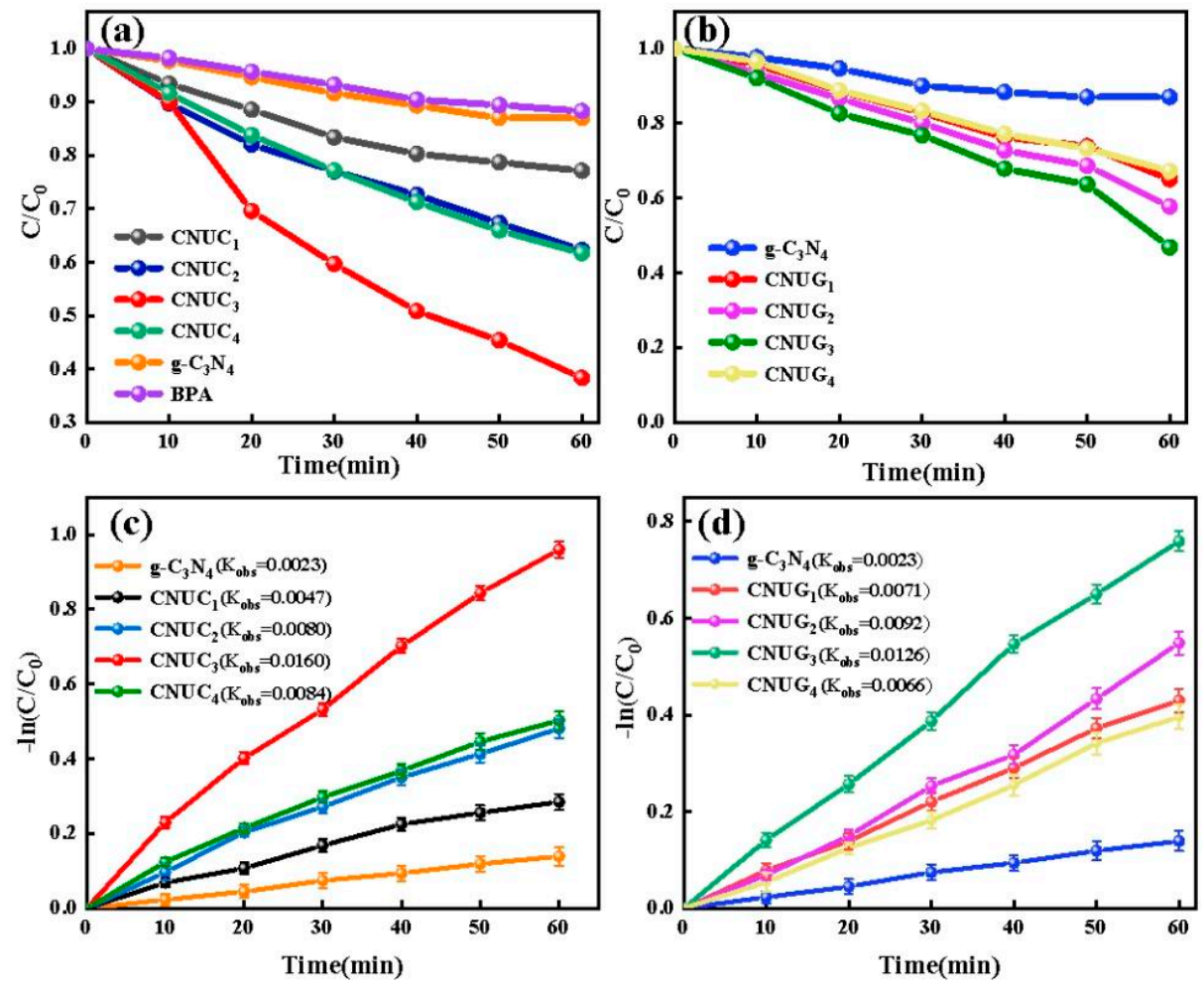

Figure 1. Photocatalytic performance test results: $(\mathbf{a}, \mathbf{b})$ Photocatalytic degradation of BPA over pure g- $\mathrm{C}_{3} \mathrm{~N}_{4}, \mathrm{CNUC}$, and CNUG samples under visible light irradiation. (c,d) Corresponding pseudofirst-order reaction kinetic fitted curves of $\mathrm{g}-\mathrm{C}_{3} \mathrm{~N}_{4}, \mathrm{CNUC}$ and $\mathrm{CNUG}$ samples. 


\subsection{Characterization of Photocatalysts}

\subsubsection{Catalysis Structure and Morphology Analysis}

The phase composition and the crystal structure of $\mathrm{g}-\mathrm{C}_{3} \mathrm{~N}_{4}, \mathrm{CNUC}_{3}$, and $\mathrm{CNUG}_{3}$ were characterized by XRD, as shown in Figure 2a. All samples revealed a typical g- $\mathrm{C}_{3} \mathrm{~N}_{4}$ layered structure, and the result show the presence of two diffraction peaks at $13.0^{\circ}$ and $27.5^{\circ}$, which were attributed to the (100) and (002) crystal planes, respectively [24]. The diffraction peak at $2 \theta=27.5^{\circ}$ was attributed to the interlayer stacking of aromatic compounds, and the diffraction peak at $2 \theta=13.0^{\circ}$ was derived from the in-plane stacking of the tris-s-triazine ring. [25]. Compared with that of $\mathrm{g}-\mathrm{C}_{3} \mathrm{~N}_{4}$, the (002) diffraction peak of $\mathrm{CNUC}_{3}$ and $\mathrm{CNUG}_{3}$ was shifted from $27.61^{\circ}$ to $27.31^{\circ}$, indicating that the interplanar stacking distance increased after O-doping.
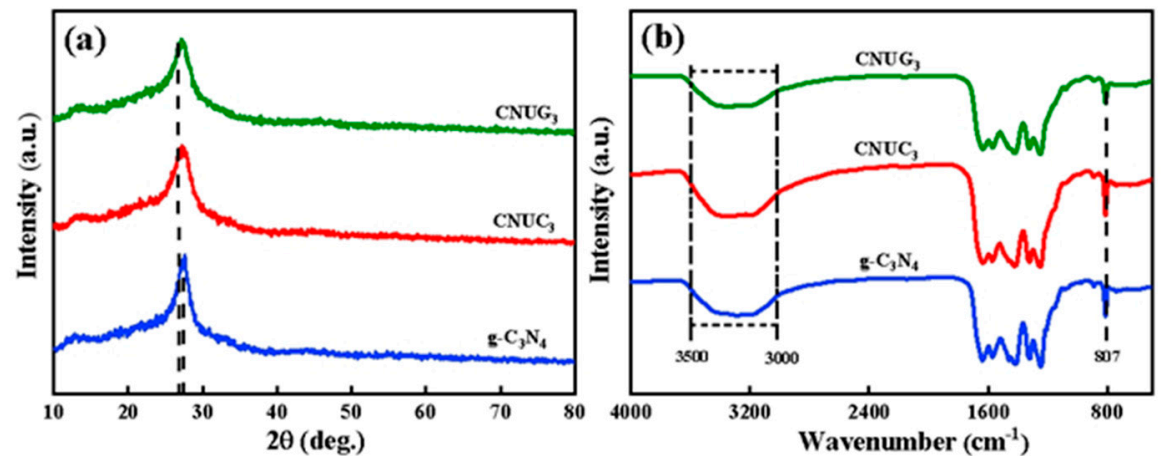

Figure 2. (a) XRD patterns; (b) FT-IR spectra of $\mathrm{g}-\mathrm{C}_{3} \mathrm{~N}_{4}, \mathrm{CNUC}_{3}$, and $\mathrm{CNUG}_{3}$.

Figure $2 \mathrm{~b}$ shows the FT-IR spectra of $\mathrm{g}-\mathrm{C}_{3} \mathrm{~N}_{4}, \mathrm{CNUC}_{3}$, and $\mathrm{CNUG}_{3}$. All of the samples revealed similar FT-IR patterns. g- $\mathrm{C}_{3} \mathrm{~N}_{4}$ had an obvious characteristic peak at about $809 \mathrm{~cm}^{-1}$, which was assigned to the tri-s-triazine ring. The multiple diffraction peaks within 1200 to $1700 \mathrm{~cm}^{-1}$ represented the stretching vibration of the $\mathrm{C}-\mathrm{N}$ heterocyclic ring [26], and the broad peak between 3000 to $3500 \mathrm{~cm}^{-1}$ was caused by the stretching vibration of $\mathrm{N}-\mathrm{H}$ and the water molecules adsorbed on the catalyst surface. [27]. Figure $2 b$ shows that the enhanced peak intensity of $\mathrm{CNUC}_{3}$ at between 3000 and $3500 \mathrm{~cm}^{-1}$ indicated the presence of more $-\mathrm{OH}$ bonds on the surface of $\mathrm{CNUC}_{3}$.

The morphologies of the $\mathrm{g}_{-} \mathrm{C}_{3} \mathrm{~N}_{4}, \mathrm{CNUC}_{3}$, and $\mathrm{CNUG}_{3}$ were characterized by SEM and TEM. As shown in Figure $3 \mathrm{a}, \mathrm{d}, \mathrm{e}$, pure $\mathrm{g}-\mathrm{C}_{3} \mathrm{~N}_{4}$ showed large bulk particles, a smooth surface and a thick $2 \mathrm{D}$ sheet-like structure, while $\mathrm{CNUC}_{3}$ had a porous structure with a skeleton shape, owing to the release of gases $\left(\mathrm{NH}_{3}, \mathrm{H}_{2} \mathrm{O}, \mathrm{CO}\right.$, and $\left.\mathrm{CO}_{2}\right)$ due to the decomposition of $\left(\mathrm{NH}_{4}\right)_{2} \mathrm{C}_{2} \mathrm{O}_{4}$ during the pyrolysis process [28]. $\mathrm{CNUG}_{3}$ showed obvious flake-like structures with some disordered pores, which might have resulted from the evolution of carbonaceous gas from glycine oxidation at high temperatures [29]. Compared with $\mathrm{CNUC}_{3}, \mathrm{CNUG}_{3}$ had fewer holes. In addition, the porous structure provided the $\mathrm{CNUC}_{3}$ and $\mathrm{CNUG}_{3}$ catalysts with a higher specific surface area and a larger pore volume, thereby exposing more active sites and resulting in enhanced photocatalytic activity. The TEM image showed that the as-prepared $\mathrm{CNUC}_{3}$ samples consisted of the ultrathin $2 \mathrm{D}$ layers with abundant mesoporous layers compared to $\mathrm{g}-\mathrm{C}_{3} \mathrm{~N}_{4}$ and $\mathrm{CNUG}_{3}$ with a compact microstructure. From the morphological point of view, consistent with the TEM image, the pore structure of $\mathrm{CNUG}_{3}$ was not as good as that of $\mathrm{CNUC}_{3}$. The knitting of ultrathin and surface porous $\mathrm{CNUC}_{3}$ nanosheets could shorten the distance between the body and the surface diffuse migration of photo-generated charges, thus inhibiting the photogenerated charges in the internal recombination. Figures $\mathrm{S} 1$ and $\mathrm{S} 2$ show the energy-dispersive $\mathrm{X}$-ray analysis maps of the $\mathrm{CNUC}_{3}$ and $\mathrm{CNUG}_{3}$ sample. The $\mathrm{C}, \mathrm{N}$, and $\mathrm{O}$ elements were uniformly dispersed on the $\mathrm{CNUC}_{3}$ and $\mathrm{CNUG}_{3}$ photocatalysts. 


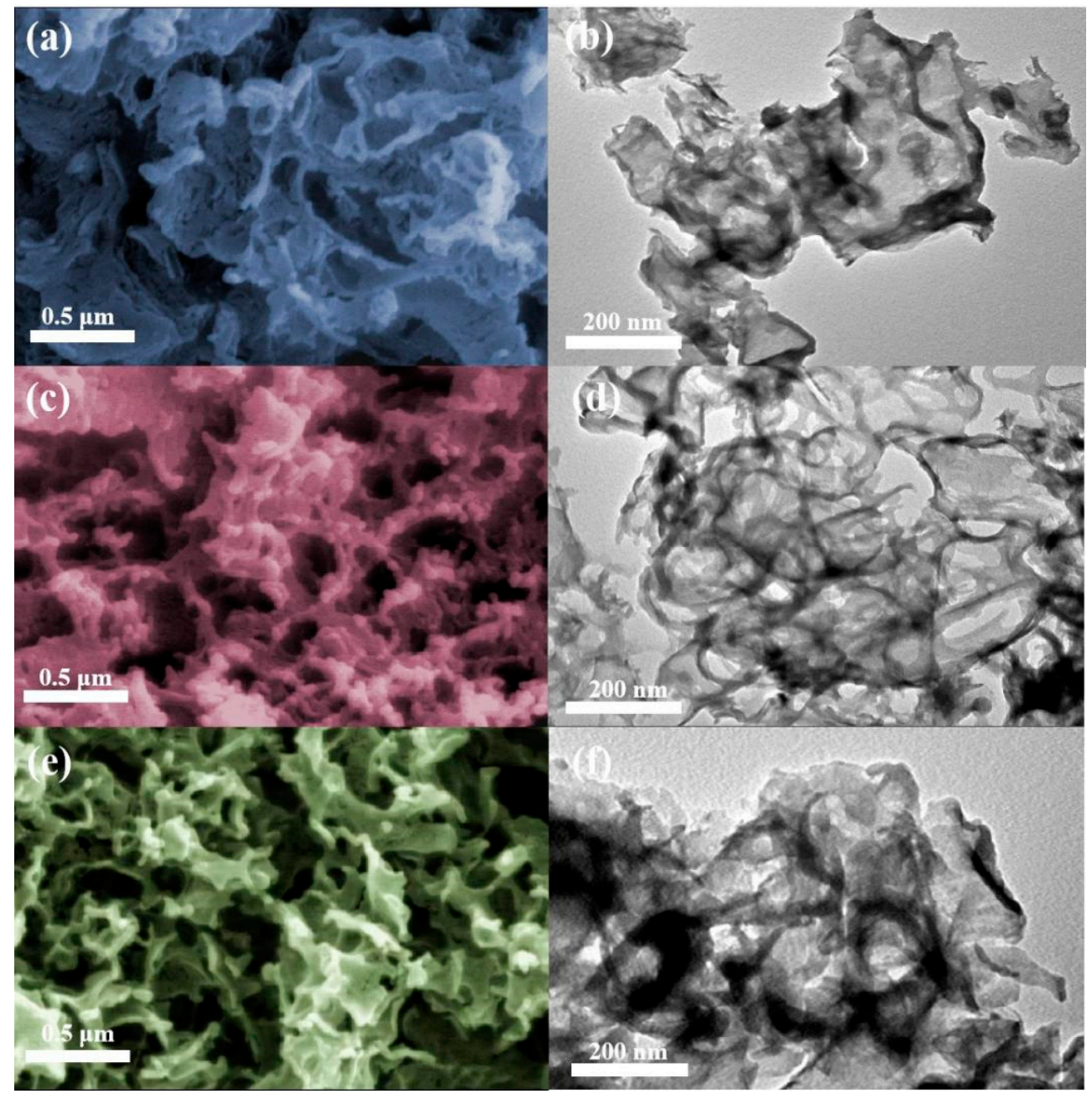

Figure 3. Morphology analysis test results: SEM images of (a) $g-\mathrm{C}_{3} \mathrm{~N}_{4},(\mathbf{b}) \mathrm{CNUC}_{3}$, and (c) $\mathrm{CNUG}_{3}$. TEM images of (d) $\mathrm{g}-\mathrm{C}_{3} \mathrm{~N}_{4},(\mathbf{e}) \mathrm{CNUC}_{3}$, and (f) $\mathrm{CNUG}_{3}$.

The $\mathrm{N}_{2}$ adsorption-desorption isotherms of the as-prepared samples are shown in Figure S3. The isotherm of the sample was type IV and the hysteresis loop was type $\mathrm{H} 3$ [30]. As displayed in Table S1, compared with $\mathrm{g}-\mathrm{C}_{3} \mathrm{~N}_{4}$ and $\mathrm{CNUG}_{3}, \mathrm{CNUC}_{3}$ showed higher pore volumes, which was consistent with the result of TEM. Furthermore, the surface area $\left(\mathrm{S}_{\mathrm{BET}}\right)$ of $\mathrm{CNUC}_{3}$ was $48.28 \mathrm{~m}^{2} \mathrm{~g}^{-1}$, which was higher than that of $\mathrm{CNUG}_{3}\left(45.27 \mathrm{~m}^{2} \mathrm{~g}^{-1}\right)$ and much higher than that of $\mathrm{g}-\mathrm{C}_{3} \mathrm{~N}_{4}\left(14.93 \mathrm{~m}^{2} \mathrm{~g}^{-1}\right)$. The increase in the surface area of the $\mathrm{CNUC}_{3}$ sample was conducive to photocatalytic performance. According to the existing literature, a larger area could increase the number of adsorption and photocatalytic reaction sites, which was conducive to photocatalytic reactions because it enhanced mass transfer and light collection efficiency.

The elemental compositions and the chemical binding states of the photocatalyst composites were analyzed by XPS. The XPS spectra of $\mathrm{g}-\mathrm{C}_{3} \mathrm{~N}_{4}, \mathrm{CNUC}_{3}$, and $\mathrm{CNUG}_{3}$ are presented in Figure 4a. In Figure $4 \mathrm{~b}$, it could be seen that the C 1s XPS spectrum of g$\mathrm{C}_{3} \mathrm{~N}_{4}$ was mainly divided into three characteristic peaks at 284.60, 288.1 and $293.5 \mathrm{eV}$. The binding energy at $284.6 \mathrm{eV}$ was indefinite carbon $(\mathrm{C}-\mathrm{C} / \mathrm{C}=\mathrm{C})$ [31]. The characteristic peak at $288.1 \mathrm{eV}$ was attributed to the $\mathrm{sp}^{2}$ bonding carbon in the s-triazine ring $(\mathrm{N}-\mathrm{C}=\mathrm{N})$, and this binding energy was the main carbon characteristic peak of g- $\mathrm{C}_{3} \mathrm{~N}_{4}$ [32]. The peak at $293.5 \mathrm{eV}$ could be assigned to $\pi$ electronic excitation [33]. The new peaks at $285.9 \mathrm{eV}$ confirmed the generation of $\mathrm{C}-\mathrm{O}$ bonds in $\mathrm{CNUC}_{3}$ and $\mathrm{CNUG}_{3}$ samples [34]. The peak area of the $\mathrm{C}-\mathrm{O}$ bond was noted to be the largest for $\mathrm{CNUC}_{3}$, indicating that the amount of oxygen doped in $\mathrm{CNUC}_{3}$ was the highest. The $\mathrm{N}$ 1s spectrum of the sample was divided into four 
characteristic peaks located at 398.5, 399.6, 400.9 and $404.2 \mathrm{eV}$. The characteristic peak of $398.5 \mathrm{eV}$ was the pyridine nitrogen of the triazine ring in $\mathrm{C}=\mathrm{N}-\mathrm{C}$. The peak with binding energy at $399.6 \mathrm{eV}$ corresponded to the bridging $\mathrm{N}$ atom in tertiary nitrogen $\left(\mathrm{N}-(\mathrm{C})_{3}\right)$. The binding energy was at 400.9 and $404.2 \mathrm{eV}$. It is attributed to the presence of nitrogen atoms in the amino group $(\mathrm{C}-\mathrm{N}-\mathrm{H})$ and $\pi$ excitation, respectively [35]. The peak area of $\mathrm{N} 1 \mathrm{~s}$ peak at $398.5 \mathrm{eV}$ attributed to the $\mathrm{C}=\mathrm{N}-\mathrm{C}$ group for $\mathrm{CNUG}_{3}$ was reduced compared with that of pure $\mathrm{g}-\mathrm{C}_{3} \mathrm{~N}_{4}$ and $\mathrm{CNUG}_{3}$. This might be due to the $\mathrm{sp}^{2}$ hybridized triazine structure introduced into the $\mathrm{N}$-containing aromatic ring in $\mathrm{CNUC}_{3}$, which caused the $\mathrm{N}$ atom to be replaced by the multi-electron $\mathrm{O}$ atom and gradually destroyed. In the spectrum of $\mathrm{O} 1 \mathrm{~s}$ in Figure $4 \mathrm{~d}$, the new peaks at $531.5 \mathrm{eV}$ for $\mathrm{CNUC}_{3}$ and $\mathrm{CNUG}_{3}$ might be attributed to the formation of $\mathrm{O}-\mathrm{C}$ species in the crystal lattice by $\mathrm{O}$ doping [36]. The peak area at $531.5 \mathrm{eV}$ for $\mathrm{CNUC}_{3}$ was higher than that of $\mathrm{CNUG}_{3}$, indicating that the $\mathrm{O}$ atom in ammonium oxalate easily replaced the $\mathrm{N}$ atom in the $\mathrm{g}-\mathrm{C}_{3} \mathrm{~N}_{4}$ structure to form $\mathrm{C}-\mathrm{O}$.
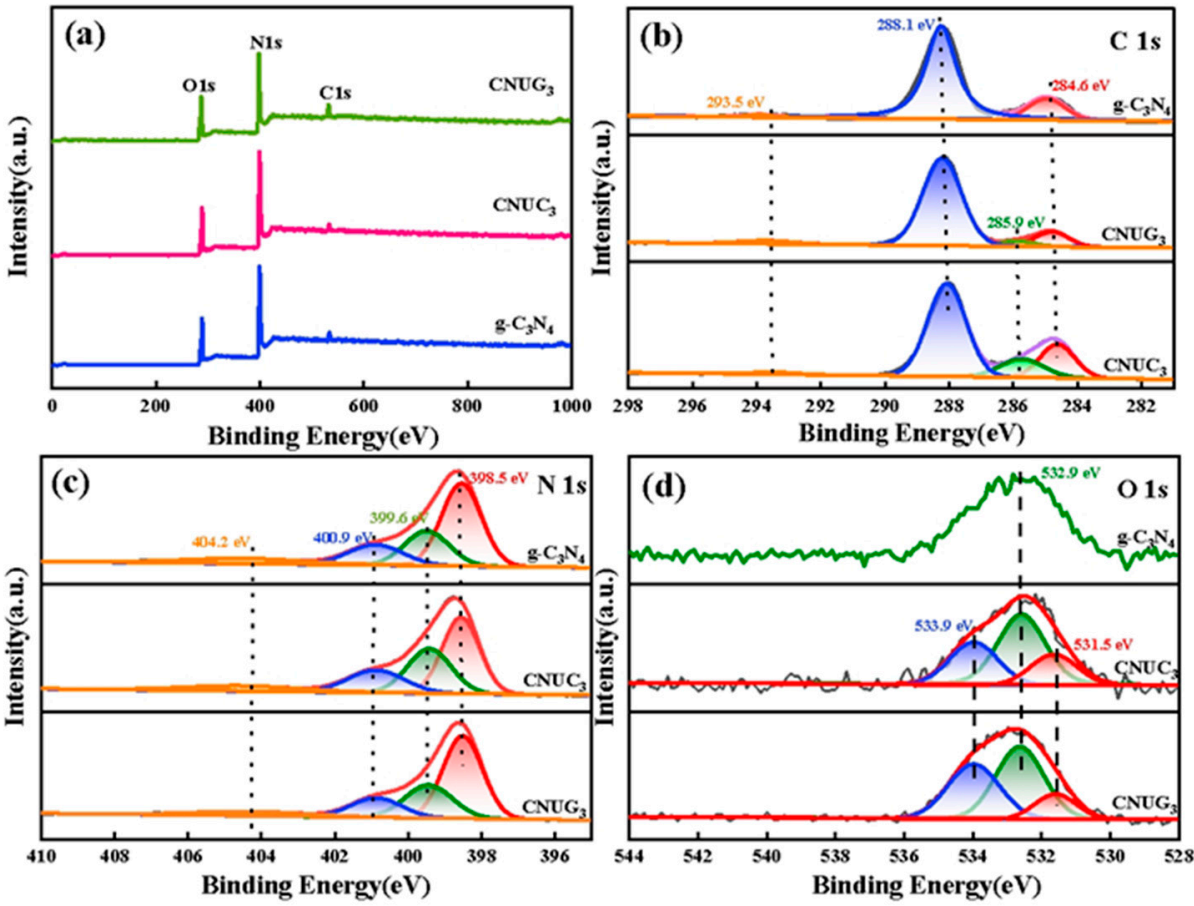

Figure 4. Elemental compositions and the chemical binding states of the photocatalyst: (a) Survey spectrum of $\mathrm{g}-\mathrm{C}_{3} \mathrm{~N}_{4} \mathrm{CNUC}_{3}$, and $\mathrm{CNUG}_{3}$. High-resolution XPS spectra of (b) $\mathrm{C} 1 \mathrm{~s}$, (c) N 1s, and (d) $\mathrm{O} 1 \mathrm{~s}$ for $\mathrm{g}-\mathrm{C}_{3} \mathrm{~N}_{4} \mathrm{CNUC}_{3}$ and $\mathrm{CNUG}_{3}$ samples.

\subsubsection{Optical and Electrochemical Properties}

To confirm the light absorption and electronic structure of the catalysts, UV-vis spectroscopy was performed on $\mathrm{g}-\mathrm{C}_{3} \mathrm{~N}_{4}, \mathrm{CNUC}_{3}$, and $\mathrm{CNUG}_{3}$. From the UV-vis spectra of g- $\mathrm{C}_{3} \mathrm{~N}_{4}, \mathrm{CNUC}_{3}$, and $\mathrm{CNUG}_{3}$ shown in Figure $5 \mathrm{a}$, we could see that all samples showed strong absorption in the visible light region. The absorption edges of $\mathrm{g}-\mathrm{C}_{3} \mathrm{~N}_{4}$ were located at around $489 \mathrm{~nm}$. Both $\mathrm{CNUC}_{3}$ and $\mathrm{CNUG}_{3}$ samples exhibited a redshifted in the absorption edges at 696 and $650 \mathrm{~nm}$, respectively. These results indicate that $\mathrm{CNUC}_{3}$ and $\mathrm{CNUG}_{3}$ could absorb a wider spectrum and more light photon energy, leading to an increase in the production of electrons and holes. Compared with $\mathrm{CNUG}_{3}, \mathrm{CNUC}_{3}$ showed a wider spectrum range, indicating a possibly improved visible light photocatalytic activity. The corresponding optical bandgap energy $(E g)$ was calculated using the following formula:

$$
\alpha h v=A\left(h v-E_{g}\right)^{n / 2}
$$


where $\alpha, h v, A$, and $E g$ represent the absorption coefficient, light energy, constant, and bandgap, respectively. The bandgap of $\mathrm{g}-\mathrm{C}_{3} \mathrm{~N}_{4}, \mathrm{CNUC}_{3}$, and $\mathrm{CNUG}_{3}$ was determined to be $2.77,2.65$, and $2.45 \mathrm{eV}$, respectively, as shown in Figure S4. Chen [18], 1.5\% SO-g- $\mathrm{C}_{3} \mathrm{~N}_{4}$, had a corresponding band gap of $2.63 \mathrm{eV}$. Compared with Chen, the $\mathrm{CNUC}_{3}$ and $\mathrm{CNUG}_{3}$ prepared in this paper significantly reduced the forbidden band width of the catalyst, and the wavelength shifts to the visible light direction, so that the catalyst could make better use of visible light. The narrow band gap could enable the catalyst to respond to visible light, shift the wavelength to the visible light direction, and the catalyst could capture more visible light photons, which helped to improve the photocatalytic performance of the catalyst.
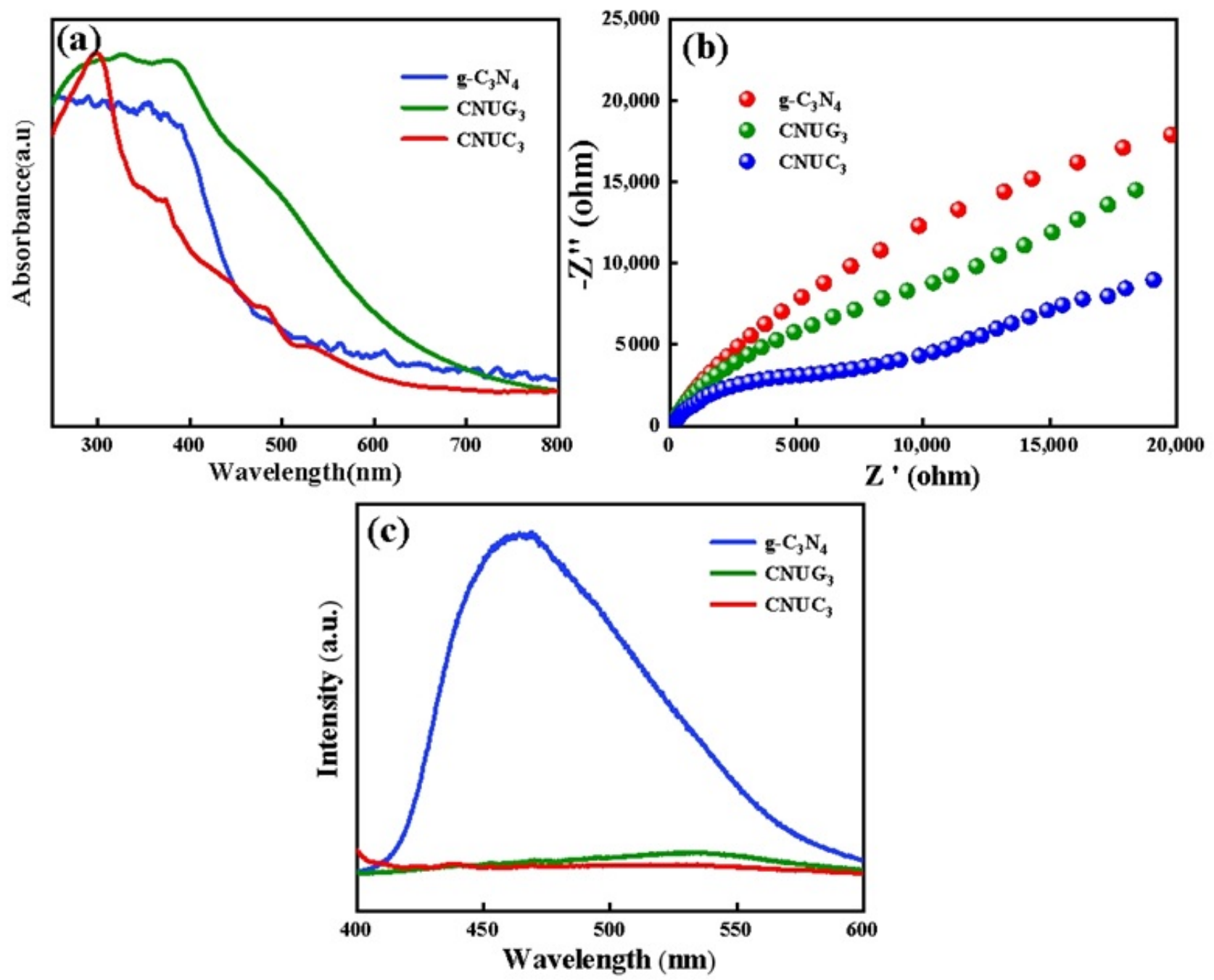

Figure 5. Electrochemical characterization: (a) UV-vis absorption spectra; (b) EIS Nyquist plots; (c) steady-state PL spectra of $\mathrm{g}-\mathrm{C}_{3} \mathrm{~N}_{4} \mathrm{CNUC}_{3}$ and $\mathrm{CNUG}_{3}$.

The separation efficiency and the transferability of photoexcited electrons and holes were evaluated using the photoluminescence (PL) emission response and EIS. Figure $5 \mathrm{~b}$ presents the EIS spectra of $\mathrm{g}-\mathrm{C}_{3} \mathrm{~N}_{4}, \mathrm{CNUC}_{3}$, and $\mathrm{CNUG}_{3}$. The smaller arc radius in the EIS Nyquist diagram, illustrated a stronger photogenerated charge separation and transferability. It could be seen from the EIS Nyquist diagram that $\mathrm{CNUC}_{3}$ had the smallest arc radius, followed by $\mathrm{CNUG}_{3}$, and $\mathrm{g}-\mathrm{C}_{3} \mathrm{~N}_{4}$ had the largest arc radius. This result shows that $\mathrm{CNUC}_{3}$ had a good photo-generated carrier separation ability and further confirms that $\mathrm{CNUC}_{3}$ had good photocatalytic activity, which was consistent with the results discussed previously. Figure $5 c$ presents the PL spectra of $\mathrm{g}-\mathrm{C}_{3} \mathrm{~N}_{4}, \mathrm{CNUC}_{3}$, and $\mathrm{CNUG}_{3}$. Generally, 
the stronger PL intensity indicated the faster combination of photogenerated charge. As shown in the steady-state PL spectra, $g-\mathrm{C}_{3} \mathrm{~N}_{4}$ depicted an obvious PL peak with a strong emission intensity. The incorporation of either $\left(\mathrm{NH}_{4}\right)_{2} \mathrm{C}_{2} \mathrm{O}_{4}$ or $\mathrm{C}_{2} \mathrm{H}_{5} \mathrm{NO}_{2}$ led to a significant reduction in the intensity of the PL peaks for $\mathrm{CNUC}_{3}$ and $\mathrm{CNUG}_{3}$, indicating the efficient separation of light-induced electron-hole pairs. Since the PL intensity was mainly derived from the recombination of photogenerated carriers in the photocatalyst, the reduction in PL intensity was crucial evidence for increasing the charge separation rate. $\mathrm{CNUC}_{3}$ showed the lowest fluorescence intensity compared with the other two samples, which was consistent with the EIS spectra. Meanwhile, the emission peaks were red-shifted from 465 to $539 \mathrm{~nm}$ due to the $\mathrm{O}$ doping, which could promote the $\pi$-electron delocalization of the $g-C_{3} N_{4}$ network.

In order to explore the intermediates and possible degradation pathways generated by BPA in the photocatalytic degradation process, LC-MS was used to analyze the mineralization evolution process of the catalyst degradation of BPA. Similar work had been carried out in the author's previous research [22]. In Figure 6, two possible BPA degradation pathways were proposed $[37,38]$. According to reports in the literature, the current active oxidative free radicals degrade BPA molecules through two possible mechanisms: $\mathrm{C}-\mathrm{C}$ bond cleavage and hydroxylation. In the first approach, the benzene ring in BPA undergoes hydroxylation reaction to form dihydroxylated BPA (wt: 259), and the OH group on the dihydroxylated BPA molecule could be further oxidized to form tetracarbonylation BPA (wt: 255), and tetracarbonylation BPA was further oxidized to produce [2E,4Z)-3-(2-(3,4dioxane)hexane-1,5-ethylene-1-yl)] hexane-2,4-dienedioic acid (wt: 287). In the second way, the $\mathrm{C}-\mathrm{C}$ bond connected to the benzene ring in BPA reacts with the active material to form 4-isopropylphenol (wt: 135), and 4-isopropylphenol was further oxidized to form 1-(2,4-dihydroxy-yphenyl) ethanone (wt: 151). Finally, all of the above aromatic compounds undergo ring-opening reactions to produce small molecular compounds, such as 1-dihydroxybutyric acid (wt: 119), valeric acid (wt: 102), and acetic acid (wt: 60), etc. These small molecular compounds with further mineralization generate $\mathrm{CO}_{2}$ and $\mathrm{H}_{2} \mathrm{O}$.

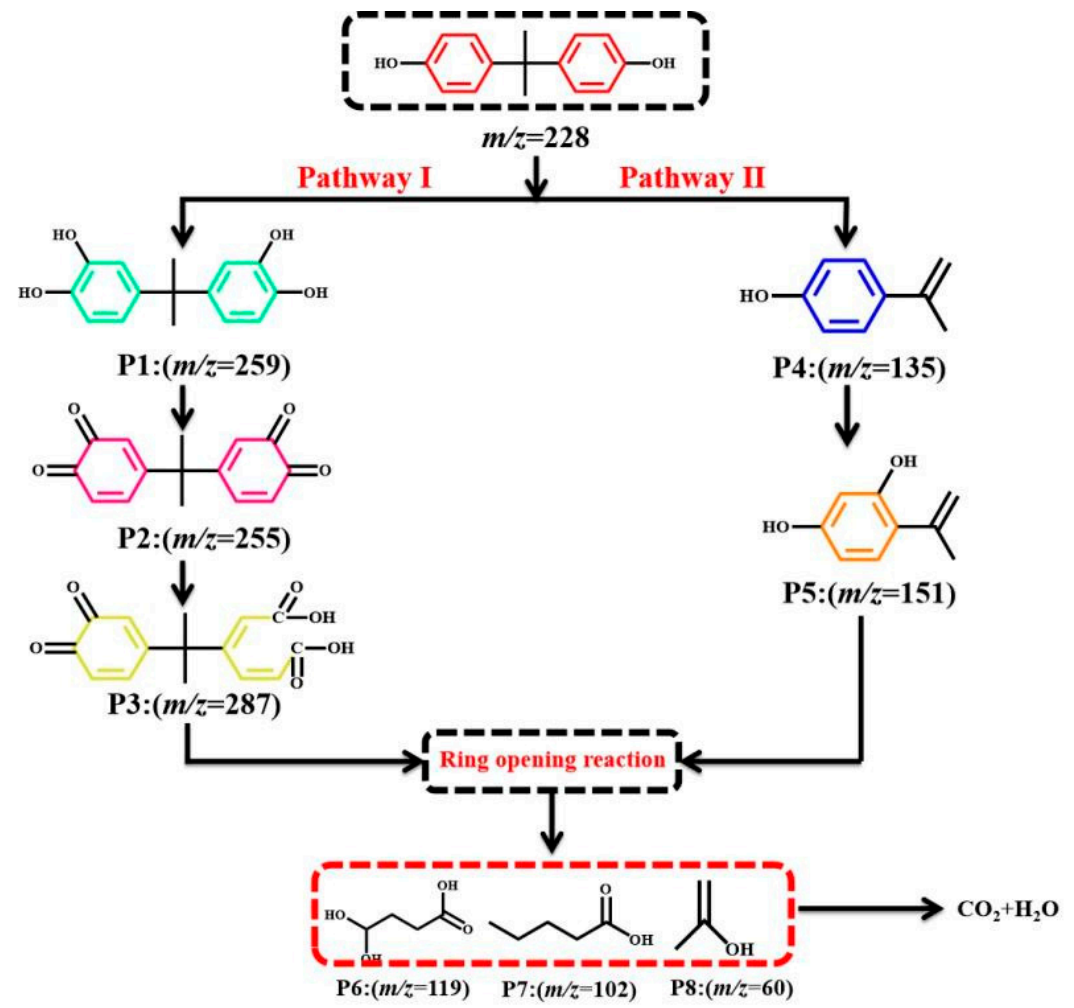

Figure 6. Possible degradation pathway of BPA under $\mathrm{CNUC}_{3}$ system. 


\subsubsection{Mechanisms of Enhanced Photocatalytic Performance}

The photocatalytic mechanism of the degradation of organic contaminants in $\mathrm{CNUC}_{3}$ samples under visible light irradiation was explored by free radical trapping experiments. tert-Butyl alcohol (t-BA), p-benzoquinone (BQ), and $\mathrm{KI}$ were taken as the quenchers for $\bullet \mathrm{OH}, \bullet \mathrm{O}_{2}{ }^{-}$, and $\mathrm{h}^{+}$, respectively. It could be seen from Figure 7a that $\mathrm{t}-\mathrm{BA}$ could slightly inhibit the degradation of BPA, and BQ and KI had a significant inhibitory effect on BPA, reducing BPA by $66 \%$ and $47.8 \%$, respectively. The above results show that $\bullet \mathrm{O}_{2}{ }^{-}$and $\mathrm{h}^{+}$ were the main active substances in the degradation of BPA and played a major role in photocatalytic degradation. The bandgaps of $\mathrm{g}-\mathrm{C}_{3} \mathrm{~N}_{4}, \mathrm{CNUC}_{3}$, and $\mathrm{CNUG}_{3}$ were discussed earlier by UV-vis diffuse reflectance spectra. The bandgap of solid solutions of g- $\mathrm{C}_{3} \mathrm{~N}_{4}$, $\mathrm{CNUC}_{3}$, and $\mathrm{CNUG}_{3}$ was $2.77,2.45$, and $2.65 \mathrm{eV}$, respectively. The XPS valence band spectra of $\mathrm{g}_{-} \mathrm{C}_{3} \mathrm{~N}_{4}, \mathrm{CNUC}_{3}$ and $\mathrm{CNUG}_{3}$ are shown in Figure $7 \mathrm{~b}$. The valence band (VB) spectra for $\mathrm{g}_{-} \mathrm{C}_{3} \mathrm{~N}_{4}, \mathrm{CNUC}_{3}$, and $\mathrm{CNUG}_{3}$ were $0.98,1.27$, and $1.13 \mathrm{eV}$, respectively, and the corresponding conduction band $(\mathrm{CB})$ calculated from the equation $\mathrm{E}_{\mathrm{CB}}=\mathrm{E}_{\mathrm{VB}}-\mathrm{E}_{\mathrm{g}}$, was $-1.79,-1.18$, and $-1.52 \mathrm{eV}$, respectively. The band structures of $\mathrm{g}-\mathrm{C}_{3} \mathrm{~N}_{4}, \mathrm{CNUC}_{3}$, and $\mathrm{CNUG}_{3}$ are presented in Figure 7c. According to previous literature reported [39], the N1 and $\mathrm{N} 4$ sites in $\mathrm{g}-\mathrm{C}_{3} \mathrm{~N}_{4}$ were replaced by oxygen atom in $\mathrm{CNUC}_{3}$ catalyst prepared by ammonium oxalate as precursor, while the $\mathrm{N} 1$ site in $\mathrm{g}-\mathrm{C}_{3} \mathrm{~N}_{4}$ was replaced by glycine as precursor [29]. Therefore, $\mathrm{CNUC}_{3}$ has a narrower band gap, which improves the visible light capture ability and photocatalytic activity.
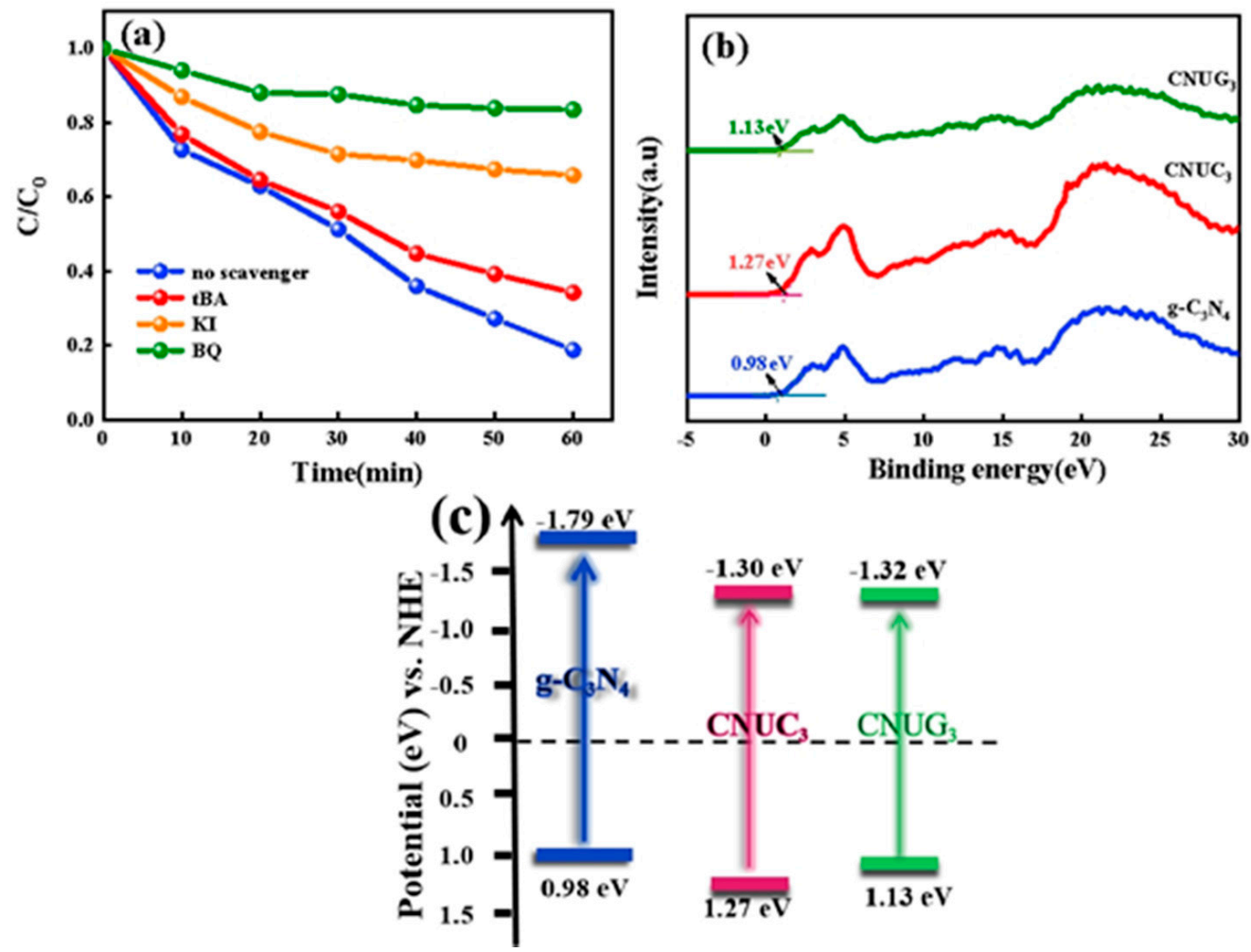

Figure 7. Mechanism discussion: (a) effect of different radical scavengers on the photodegradation of BPA over $\mathrm{CNUC}_{3}$; (b) XPS VB spectra; (c) schematic illustration of the energy-level diagrams of the as-obtained catalysts.

Based on the above experiment and analysis, a possible mechanism for the photodegradation of BPA by $\mathrm{CNUC}_{3}$ under visible light irradiation was proposed, as shown in Figure 8. First, under the irradiation of visible light, photogenerated $\mathrm{e}^{-}$transferred from the VB to the $\mathrm{CB}$ of $\mathrm{CNUC}_{3}$ and formed a conjugated delocalized $\pi$ system, because the potential on $\mathrm{CNUC}_{3} \mathrm{CB}(-1.18$ to $-1.79 \mathrm{eV})$ was more negative than the $\mathrm{O}_{2} / \bullet \mathrm{O}_{2}{ }^{-}(-0.33 \mathrm{eV}$ vs. NHE$)$. The $\mathrm{e}^{-}$on $\mathrm{CB}$ could directly react with $\mathrm{O}_{2}$ on the surface of the catalyst to produce $\bullet \mathrm{O}_{2}{ }^{-}$. 
Due to the strong oxidation ability of $\bullet \mathrm{O}_{2}{ }^{-}$radicals, it could directly mineralize BPA into $\mathrm{CO}_{2}$ and $\mathrm{H}_{2} \mathrm{O}$. Besides, the $\mathrm{VB}$ potential of $\mathrm{CNUC}_{3}$ was lower than the standard oxidation-reduction potential of $\mathrm{OH}^{-} / \bullet \mathrm{OH}\left(+2.38 \mathrm{eV}\right.$ vs. NHE) [27], so that $\mathrm{h}^{+}$left on the $\mathrm{VB}$ of $\mathrm{CNUC}_{3}$ could not oxidize $\mathrm{OH}^{-}$to produce $\bullet \mathrm{OH}$ kinetically. However, the $\mathrm{h}^{+}$ on $\mathrm{CNUC}_{3} \mathrm{VB}$ could directly react with $\mathrm{BPA}$ to produce $\mathrm{CO}_{2}$ and $\mathrm{H}_{2} \mathrm{O}$. On the one hand, $\mathrm{O}$ atom doping was introduced and porous structure built an inter-bandgap, leading to a narrow bandgap, which could increase the visible light absorption and light quantum efficiencies and further enhanced the photocatalytic activity under visible light. On the other hand, O-doped $\mathrm{g}-\mathrm{C}_{3} \mathrm{~N}_{4}$ could effectively improve the separation of photo-generated carriers and accelerated the improvement of charge transfer efficiency, thereby enhancing its photocatalytic activity.

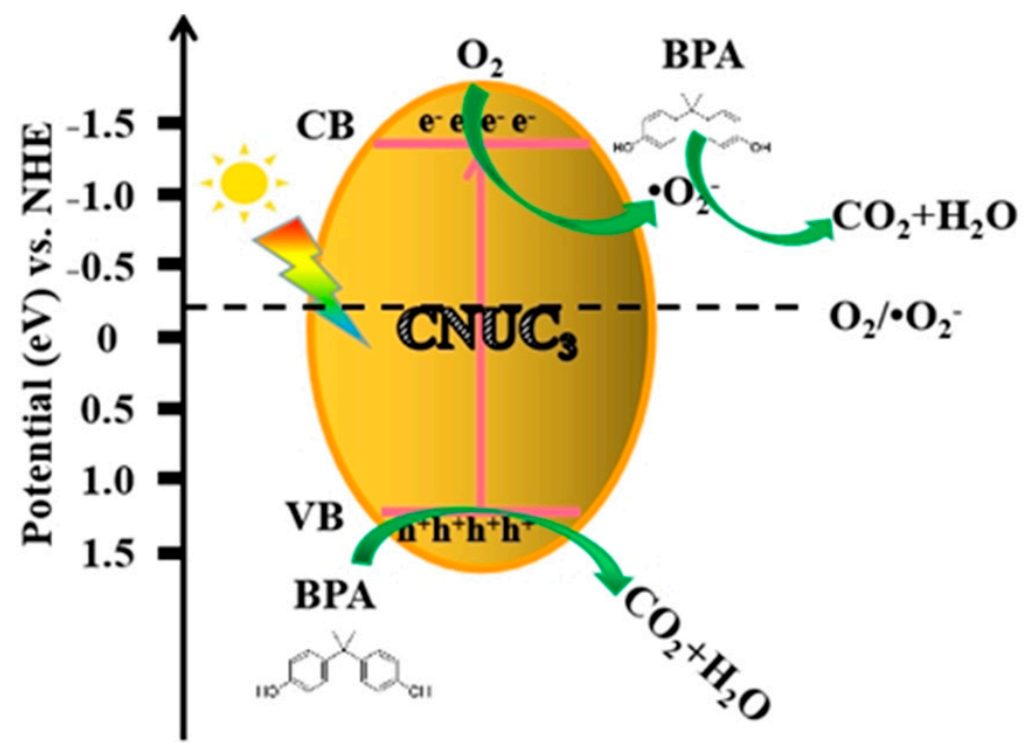

Figure 8. Schematic diagram of the $\mathrm{CNUC}_{3}$ under visible light irradiation.

In addition to investigating the photocatalytic activity of the catalyst, the reusability of the photocatalyst was also the key to its industrialization. Five photocatalytic cycle experiments were carried out on $\mathrm{CNUC}_{3}$ to evaluate its light stability and reusability. Figure 9 a was a photocatalytic cycle experiment diagram. It could be seen from the figure that after five cycles of the catalyst, the degradation efficiency of BPA was 75\%. During the reaction process, a small amount of $\mathrm{CNUC}_{3}$ powder would be removed due to the continuous stirring process, and a small amount of catalyst would also be removed during the washing and drying process of the catalyst. It could be seen from the figure that after the photocatalytic reaction was cycled three times, the catalyst activity tends to be stable. This phenomenon showed that $\mathrm{CNUC}_{3}$ had good stability and reusability. In addition, in order to explore whether the crystal form and chemical species of the catalyst changed after five cycles, the $\mathrm{CNUC}_{3}$ was characterized by XRD and FT-IR. Figure $9 \mathrm{~b}$ was the XRD pattern after five cycles. From the figure, it could be seen that after five cycles of the catalyst, all crystal faces hardly changed. Figure $9 \mathrm{c}$ was the FT-IR diagram after five cycles. The results show that the characteristic peaks of the FT-IR spectrum before and after the reaction hardly changed. From the above results, $\mathrm{CNUC}_{3}$ had good chemical stability and can effectively inhibit photo-corrosion performance. 

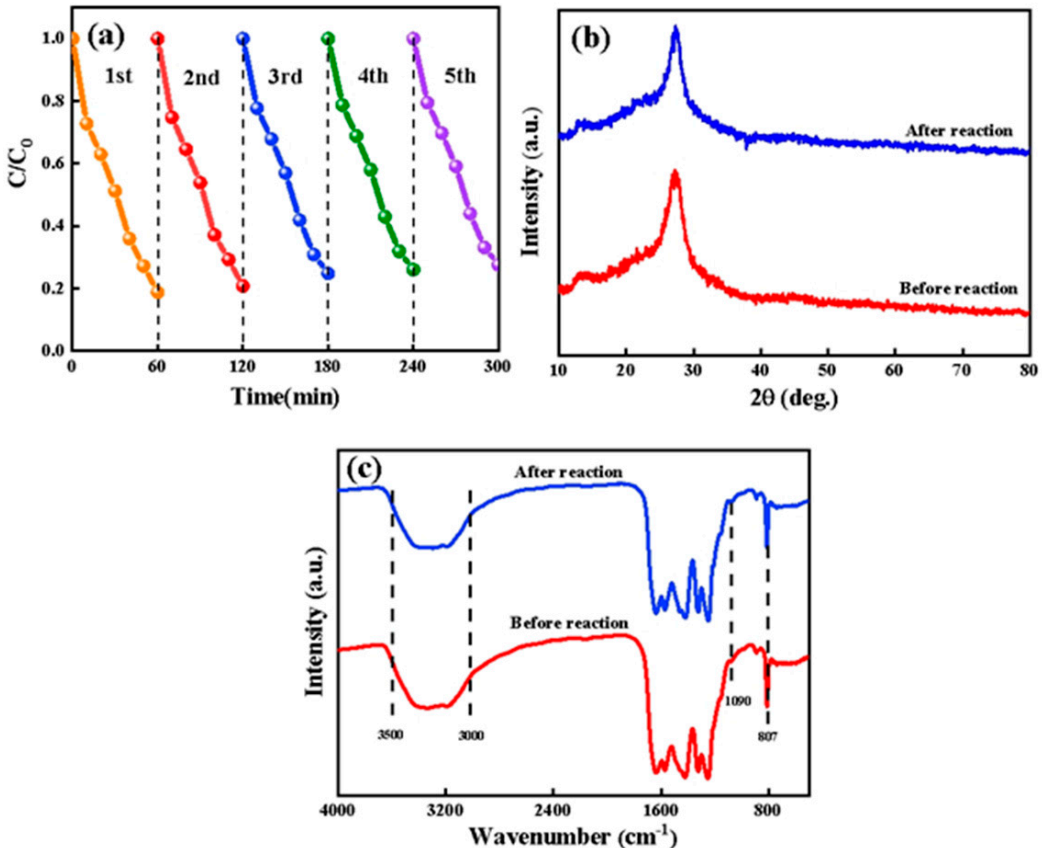

Figure 9. Catalyst stability research: (a) Reusability evaluation of $\mathrm{CNUC}_{3}$ for the photodegradation of BPA under visible light; (b) XRD patterns; (c) FT-IR spectra of the $\mathrm{CNUC}_{3}$ sample before and after five photocatalytic reaction cycles.

\section{Conclusions}

In summary, we successfully fabricated O-doped porous $\mathrm{g}-\mathrm{C}_{3} \mathrm{~N}_{4}$ nanosheet photocatalysts via thermal copolymerization with urea and ammonium oxalate or glycine as raw materials. A large number of pores were formed by gas generated from the copolymerization decomposition of ammonium oxalate, resulting in an enlarged specific surface area. At the same time, $\mathrm{O}$ doping adjusted the $\mathrm{g}-\mathrm{C}_{3} \mathrm{~N}_{4}$ bandgap engineering to narrow the bandgap and expand the visible light response.

(1) Under visible light irradiation, the optimum photocatalytic efficiency of $\mathrm{CNUC}_{3}$ and $\mathrm{CNUG}_{3}$ nanosheets was enhanced by nearly seven and five times, respectively, more than that of $\mathrm{g}-\mathrm{C}_{3} \mathrm{~N}_{4}$ for BPA degradation in $60 \mathrm{~min}$. $\mathrm{CNUC}_{3}$ was found to present high stability and excellent recycling in the photocatalytic degradation processes.

(2) Free radical capture experiments have confirmed that $\mathrm{h}^{+}$and $\bullet \mathrm{O}_{2}{ }^{-}$were the main active species that degrade $\mathrm{BPA}$, and $\bullet \mathrm{O}_{2}{ }^{-}$could reduce BPA to produce $\mathrm{CO}_{2}$ and $\mathrm{H}_{2} \mathrm{O}$. Meanwhile, $\mathrm{h}^{+}$had strong oxidizing ability and could directly mineralize BPA into small molecular substances.

(3) Therefore, this work may open a new route to fabricate nonmetal-modified $\mathrm{g}-\mathrm{C}_{3} \mathrm{~N}_{4}$ based catalysts with high degradation efficiency under visible light irradiation. Moreover, it may provide new inspiration for improving the activities of photocatalysts.

Supplementary Materials: The following supplementary materials can be downloaded at: https:/ / www.mdpi.com/article/10.3390/ma15041391/s1, Figure S1: Mapping images of CNUC3; Figure S2: Mapping images of CNUG3; Figure S3: N2 adsorption-desorption isotherms of g-C3N4 CNUC3 and CNUG3; Table S1: Textural properties of the prepared samples; Figure S4: Bandgap value, estimated using a related curve of $(\alpha \mathrm{h} v)^{1 / 2}$ versus photon energy.

Author Contributions: Formal analysis, J.Z.; methodology, J.Z.; writing—original draft, J.Z., conceptualization, Y.Z. (Yongjie Zheng); resources, Y.Z. (Yongjie Zheng), J.T.; validation, Y.Z. (Yongjie Zheng); writing—review, H.Z.; supervision, H.Z.; software, T.J.; writing—review \& editing, T.J., Y.Z. (Yunpeng Zhao); investigation, Y.Z. (Yunpeng Zhao); project administration, J.T. All authors have read and agreed to the published version of the manuscript. 
Funding: This work is supported by the Basic Business Project of Education Department of Heilongiiang Province (135309109), the Basic Scientific Research Funds of Heilongjiang Provincial Universities (YSTSXK201810 \& YSTSXK201850), and the National Natural Science Foundation of China (No. 52172092).

\section{Institutional Review Board Statement: Not applicable.}

Informed Consent Statement: Not applicable.

Data Availability Statement: The data presented in this study are available upon request from the corresponding author.

Conflicts of Interest: The authors declare no conflict of interest.

\section{References}

1. Wang, Q.; Yang, H.; Yang, M.; Yu, Y.; Yan, M.; Zhou, L.; Liu, X.; Xiao, S.; Yan, Y.; Wang, Y.; et al. Toxic effects of bisphenol A on goldfish gonad development and the possible pathway of BPA disturbance in female and male fish reproduction. Chemosphere 2019, 221, 235-245. [CrossRef] [PubMed]

2. Cong, Y.Q.; Zhang, W.H.; Ding, W.C.; Zhang, T.T.; Zhang, Y.; Chi, N.P.; Wang, Q. Fabrication of electrochemically-modified $\mathrm{BiVO}_{4}-\mathrm{MoS}_{2}-\mathrm{Co}_{3} \mathrm{O}_{4}$ composite film for bisphenol A degradation. J. Environ. Sci. 2021, 102, 341-351. [CrossRef] [PubMed]

3. Liang, P.; Meng, D.D.; Liang, Y.; Wang, Z.; Zhang, C.; Wang, S.B.; Zhang, Z.H. Cation deficiency tuned LaCoO ${ }_{3}-\delta$ perovskite for peroxymonosulfate activation towards bisphenol A degradation. Chem. Eng. J. 2020, 409, 128196. [CrossRef]

4. Han, Q.; Wang, H.J.; Dong, W.Y.; Liu, T.Z.; Yin, Y.L.; Fan, H.K. Degradation of bisphenol A by ferrate (VI) oxidation: Kinetics, products and toxicity assessment. Chem. Eng. J. 2015, 262, 34-40. [CrossRef]

5. Zhao, J.G.; Chen, X.R.; Liu, F.K.; Yang, N.; Huang, H.; Zhao, J. Mechanism of toxicity formation and spatial distribution in activated sludge treating synthetic effluent containing bisphenol A (BPA). Chem. Eng. J. 2014, 250, 91-98. [CrossRef]

6. Guo, W.L.; Hu, W.; Pan, J.M.; Zhou, H.C.; Guan, W.; Wang, X.; Dai, J.D.; Xu, L.C. Selective adsorption and separation of BPA from aqueous solution using novel molecularly imprinted polymers based on kaolinite $/ \mathrm{Fe}_{3} \mathrm{O}_{4}$ composites. Chem. Eng. J. 2011, 171, 603-611. [CrossRef]

7. Chen, Y.N.; Zhu, G.Q.; Hojamberdiev, M.; Gao, J.Z.; Zhu, R.L.; Wang, C.H.; Wei, X.M.; Liu, P. Three-dimensional Ag $2 \mathrm{O}^{-} \mathrm{Bi}_{5} \mathrm{O}_{7} \mathrm{I}$ $\mathrm{p}-\mathrm{n}$ heterojunction photocatalyst harnessing UV-vis-NIR broad spectrum for photodegradation of organic pollutants. J. Hazard. Mater. 2018, 344, 42-54. [CrossRef]

8. Ahamad, T.; Naushad, M.; Al-Shahrani, T.; Al-hokbany, N.; Alshehri, S.M. Preparation of chitosan based magnetic nanocomposite for tetracycline adsorption: Kinetic and thermodynamic studie. Int. J. Biol. Macromol. 2020, 147, 258-267. [CrossRef]

9. Wei, M.Y.; Gao, L.; Li, J.; Fang, J.; Cai, W.X.; Li, X.X.; Xu, A.H. Activation of peroxymonosulfate by graphitic carbon nitride loaded on activated carbon for organic pollutants degradation. J. Hazard. Mater. 2016, 316, 60-68. [CrossRef]

10. Wang, X.C.; Maeda, K.; Thomas, A.; Takanabe, K.; Xin, G.; Carlsson, J.M. A metal-free polymeric photocatalyst for hydrogen production from water under visible light. Nat. Mater. 2009, 8, 76-80. [CrossRef]

11. Xiang, Q.J.; Li, F.; Zhang, D.N.; Liao, Y.L.; Zhou, H.P. Plasma-based surface modification of g- $\mathrm{C}_{3} \mathrm{~N}_{4}$ nanosheets for highly efficient photocatalytic hydrogen evolution. Appl. Surf. Sci. 2019, 495, 143520. [CrossRef]

12. Tian, L.; Li, J.Y.; Liang, F.; Wang, J.K.; Li, S.S.; Zhang, H.J.; Zhang, S.W. Molten salt synthesis of tetragonal carbon nitride hollow tubes and their application for removal of pollutants from wastewater. Appl. Catal. B Environ. 2018, 225, 307-313. [CrossRef]

13. Yu, W.W.; Zhang, T.; Zhao, Z.K. Garland-like intercalated carbon nitride prepared by an oxalic acid-mediated assembly strategy for highly-efficient visible-light-driven photoredox catalysis. Appl. Catal. B Environ. 2020, 278, 119342. [CrossRef]

14. Yang, Y.; Zhang, C.; Huang, D.L.; Zeng, G.M.; Huang, J.H.; Lai, C.; Zhou, C.Y.; Wang, W.J.; Guo, H.; Xue, W.J. Boron nitride quantum dots decorated ultrathin porous $\mathrm{g}-\mathrm{C}_{3} \mathrm{~N}_{4}$ : Intensified exciton dissociation and charge transfer for promoting visible-lightdriven molecular oxygen activation. Appl. Catal. B Environ. 2018, 245, 87-99. [CrossRef]

15. Bfaqeer, A.; Tahir, M.; Amin, N.A.S. Well-designed $\mathrm{ZnV}_{2} \mathrm{O}_{6} / g-\mathrm{C}_{3} \mathrm{~N}_{4} 2 \mathrm{D} / 2 \mathrm{D}$ nanosheets heterojunction with faster charges separation via $\mathrm{pCN}$ as mediator towards enhanced photocatalytic reduction of $\mathrm{CO}_{2}$ to fuels. Appl. Catal. B Environ. 2019, 242, 312-326. [CrossRef]

16. Li, K.; Xie, X.; Zhang, W.D. Porous Graphitic carbon nitride derived from melamine-ammonium oxalate stacking sheets with excellent photocatalytic hydrogen evolution activity. ChemCatChem 2016, 8, 2128-2135. [CrossRef]

17. Jiang, L.B.; Yuan, X.Z.; Zeng, G.M.; Liang, J.; Wu, Z.B.; Yu, H.B.; Mo, D.; Wang, H.; Xiao, Z.H.; Zhou, C.Y. Nitrogen self-doped $\mathrm{g}-\mathrm{C}_{3} \mathrm{~N}_{4}$ nanosheets with tunable band structures for enhanced photocatalytic tetracycline degradation. J. Colloid Interface Sci. 2019, 536, 17-29. [CrossRef]

18. Chen, H.; Yao, J.H.; Qiu, P.X.; Xu, C.M.; Jiang, F.; Wang, X. Facile surfactant assistant synthesis of porous oxygen-doped graphitic carbon nitride nanosheets with enhanced visible light photocatalytic activity. Mater. Res. Bull. 2017, 91, 42-48. [CrossRef]

19. Zhu, D.D.; Zhou, Q.X. Nitrogen doped g- $\mathrm{C}_{3} \mathrm{~N}_{4}$ with the extremely narrow band gap for excellent photocatalytic activities under visible light. Appl. Catal. B Environ. 2020, 281, 119474. [CrossRef]

20. Jourshabani, M.; Shariatinia, Z.; Badiei, A. Sulfur-Doped Mesoporous carbon nitride decorated with Cu particles for efficient photocatalytic degradation under visible-light irradiation. J. Phys. Chem. C 2017, 121, 19239-19253. [CrossRef] 
21. Tong, Z.W.; Yang, D.; Li, Z.; Nan, Y.H.; Ding, F.; Shen, Y.C.; Jiang, Z.Y. Thylakoid-Inspired multishell g-C ${ }_{3} \mathrm{~N}_{4}$ nanocapsules with Enhanced visible-light harvesting and electron transfer properties for high-efficiency photocatalysis. Acs Nano 2017, 11, 1103-1112. [CrossRef] [PubMed]

22. Zhang, J.J.; Zheng, Y.J.; Zheng, H.S. A 2D/3D g- $\mathrm{C}_{3} \mathrm{~N}_{4} /$ BiOI heterostructure nano-sphere with oxygen-doped for enhanced visible light-driven photocatalytic activity in environmental remediation. J. Alloys Compd. 2021, 897, 163044. [CrossRef]

23. Li, J.H.; Shen, B.A.; Hong, Z.H.; Lin, B.Z.; Gao, B.F.; Chen, Y.L. A facile approach to synthesize novel oxygen-doped g-C ${ }_{3} \mathrm{~N}_{4}$ with superior visible-light photoreactivity. Chem. Comm. 2012, 48, 12017-12019. [CrossRef] [PubMed]

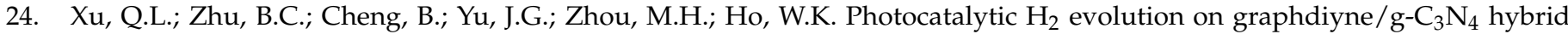
nanocomposites. Appl. Catal. B Environ. 2019, 255, 117770. [CrossRef]

25. Wang, L.J.; Zhou, G.; Tian, Y.; Yan, L.K.; Deng, M.X.; Yang, B.; Kang, Z.H.; Sun, H.Z. Hydroxyl decorated g-C ${ }_{3} \mathrm{~N}_{4}$ nanoparticles with narrowed bandgap for high efficient photocatalyst design. Appl. Catal. B Environ. 2019, 244, 262-271. [CrossRef]

26. Yang, B.; Zhao, J.J.; Yang, W.D.; Sun, X.Y.; Wang, R.J.; Jia, X. A step-by-step synergistic stripping approach toward ultra-thin porous $\mathrm{g}-\mathrm{C}_{3} \mathrm{~N}_{4}$ nanosheets with high conduction band position for photocatalystic $\mathrm{CO}_{2}$ reduction. J. Colloid Interface Sci. 2021, 589, 179-186. [CrossRef]

27. Uddin, A.; Muhmood, T.; Guo, Z.C.; Gu, J.Y.; Chen, H.; Jiang, F. Hydrothermal synthesis of 3D/2D heterojunctions of $\mathrm{ZnIn}_{2} \mathrm{~S}_{4}$ / oxygen doped g- $\mathrm{C}_{3} \mathrm{~N}_{4}$ nanosheet for visible light driven photocatalysis of 2,4-dichlorophenoxyacetic acid degradation. J. Alloys Compd. 2020, 845, 156206. [CrossRef]

28. Zhang, Y.W.; Liu, J.H.; Wu, G.; Chen, W. Porous graphitic carbon nitride synthesized via direct polymerization of urea for efficient sunlight-driven photocatalytic hydrogen production. Nanoscale 2012, 4, 5300-5303. [CrossRef]

29. Li, G.S.; Shi, J.L.; Zhang, G.; Fang, Y.X.; Anpo, M.; Wang, X.C. The facile synthesis of graphitic carbon nitride from amino acid and urea for photocatalytic $\mathrm{H}_{2}$ production. Res. Chem. Intermed. 2017, 43, 5137-5152. [CrossRef]

30. Jiang, Z.F.; Qian, K.; Zhu, C.Z.; Sun, H.L.; Wan, W.M.; Xie, J.M.; Li, H.M.; Wong, P.K.; Yuan, S.Q. Carbon nitride coupled with $\mathrm{CdS}-\mathrm{TiO}_{2}$ nanodots as 2D/0D ternary composite with enhanced photocatalytic $\mathrm{H}_{2}$ evolution: A novel efficient three-level electron transfer process. Appl. Catal. B Environ. 2017, 210, 194-204. [CrossRef]

31. Deng, Y.C.; Tang, L.; Zeng, G.M.; Zhu, Z.J.; Yan, M.; Zhou, Y.Y.; Wang, J.J.; Liu, Y.N. Insight into highly efficient simultaneous photocatalytic removal of $\mathrm{Cr}(\mathrm{VI})$ and 2,4-diclorophenol under visible light irradiation by phosphorus doped porous ultrathin $\mathrm{g}_{-} \mathrm{C}_{3} \mathrm{~N}_{4}$ nanosheets from aqueous media: Performance and reaction mechanism. Appl. Catal. B Environ. 2017, 203, 343-354. [CrossRef]

32. Li, G.X.; Li, Y.L.; Liu, H.B.; Guo, Y.B.; Li, Y.J.; Zhu, D.B. Architecture of graphdiyne nanoscale films. Chem. Commun. 2010, 46, 3256-3258. [CrossRef] [PubMed]

33. She, X.J.; Wu, J.J.; Zhong, J.; Xu, H.; Yang, Y.C.; Vajtai, R.; Lou, J.; Liu, Y.; Du, D.L.; Li, H.M. Oxygenated monolayer carbon nitride for excellent photocatalytic hydrogen evolution and external quantum efficiency. Nano Energy 2016, 27, 138-146. [CrossRef]

34. Oh, J.; Yoo, R.J.; Kim, S.Y.; Lee, Y.J.; Kim, D.W.; Park, S. Oxidized carbon nitrides: Water-dispersible, atomically thin carbon nitride-based nanodots and their performances as bioimaging probes. Chem. Eur. J. 2015, 21, 6241-6246. [CrossRef]

35. Shi, Y.H.; Huang, J.H.; Zeng, G.M.; Cheng, W.J.; Yu, H.B.; Gu, Y.L.; Shi, L.X.; Yi, K.X. Stable, metal-free, visible-light-driven photocatalyst for efficient removal of pollutants: Mechanism of action. J. Colloid Interface Sci. 2018, 531, 433-443. [CrossRef]

36. Yang, L.Q.; Huang, J.F.; Shi, L.; Cao, L.Y.; Yu, Q.; Jie, Y.N.; Fei, J.; Ouyang, H.B.; Ye, J.H. A surface modification resultant thermally oxidized porous $g-\mathrm{C}_{3} \mathrm{~N}_{4}$ with enhanced photocatalytic hydrogen production. Appl. Catal. B Environ. 2017, 204, 335-345. [CrossRef]

37. Yang, S.; Qiu, X.; Jin, P.; Dzakpasu, M.; Wang, X.; Zhang, Q.; Zhang, L.; Yang, L.; Ding, D.; Wang, W. MOF-templated synthesis of $\mathrm{CoFe}_{2} \mathrm{O}_{4}$ nanocrystals and its coupling with peroxymonosulfate for degradation of bisphenol A. Chem. Eng. J. 2018, 353, 329-339. [CrossRef]

38. Yu, W.; Wan, S.; Yuan, D.; Sun, L.; Wang, Y. Microwave solvothermal-assisted calcined synthesis of $\mathrm{Bi}_{2} \mathrm{~W}_{\mathrm{x}} \mathrm{Mo}_{1-\mathrm{X}} \mathrm{O}_{6}$ solid solution photocatalysts for degradation and detoxification of bisphenol A under simulated sunlight irradiation. Sep. Purif. Technol. 2021, 275, 119175. [CrossRef]

39. Zhang, S.; Yang, L.; Gu, P.C.; Ma, R.; Wen, T.; Zhao, X.G. Enhanced photodegradation of toxic organic pollutants using dualoxygen-doped porous g-C3N4: Mechanism exploration from both experimental and DFT studies. Appl. Catal. B Environ. 2019, 248, 1-10. [CrossRef] 